\title{
ANALISIS PERUBAHAN MASSA BAHAN FISIL DAN NON FISIL DALAM TERAS PWR 1000 MWe DENGAN ORIGEN-ARP 5.1
}

\author{
Anis Rohanda \\ Pusat Teknologi dan Keselamatan Reaktor Nuklir (PTKRN) - BATAN \\ Kawasan PUSPIPTEK Gd. No. 80 Serpong, Tangerang Selatan 15310 \\ anis_rohanda@batan.go.id \\ Diterima editor: 9 Januari 2015 \\ Direvisi editor: 4 Februari 2015 \\ Disetujui untuk publikasi: 9 Februari 2015
}

\begin{abstract}
ABSTRAK
ANALISIS PERUBAHAN MASSA BAHAN FISIL DAN NON FISIL DALAM TERAS PWR 1000 MWe DENGAN ORIGEN-ARP 5.1. Teras reaktor merupakan tempat terjadinya reaksi pembelahan (fisi) yang terkendali. Komponen reaktor seperti bahan bakar, kelongsong (cladding) dan air pendingin memiliki peranan penting dalam keberlangsungan reaksi fisi. Reaksi fisi mengakibatkan terbentuknya sejumlah nuklida hasil fisi dan hasil aktivasi. Hasil fisi berasal dari reaksi tangkapan neutron termal dengan bahan fisil sedangkan hasil aktivasi berasal dari interaksi bahan non fisil seperti material kelongsong dan pendingin oleh neutron dan gamma. Pada setiap pengoperasian suatu reaktor, informasi perubahan massa bahan fisil dan non fisil sangat berguna untuk manajemen bahan bakar dalam teras, seperti pengaturan reaktivitas, optimasi dan pemuatan bahan bakar. Untuk itu perlu dilakukan penelitian mengenai perubahan bahan fisil dan non fisil tersebut dalam teras reaktor. Hal ini dapat dilakukan dengan mengamati perubahan massa dari material dalam teras reaktor. Penelitian ini memiliki tujuan untuk mengetahui perubahan massa unsur penyusun material dalam teras, seperti massa dari unsur penyusun elemen bahan bakar nuklir, kelongsong dan air pendingin setelah digunakan dalam teras. Dari perubahan massa tersebut dapat diketahui fraksi bakar atau tingkat konsumsi bahan bakar yang digunakan. Penelitian dilakukan pada basis reaktor PLTN tipe PWR buatan pabrikan asal Amerika Serikat berdaya 1000 MWe dengan menggunakan code penghitung inventori hasil fisi ORIGEN-ARP 5.1, yaitu versi terbaru dari ORIGEN dengan library khusus reaktor daya. Hasil analisis menunjukkan bahwa bahan fisil U-235 mengalami pengurangan massa hingga 58\% atau lebih dari separuhnya dari massa U-235 awal untuk tiap kali siklus operasi. Bahan fertil U-238 hanya mengalami pengurangan massa sekitar 2\% dari massa awalnya tiap kali siklus operasi. Lain halnya dengan bahan non fisil yang mengalami perubahan massa yang berbeda-beda untuk tiap kali siklus operasinya yang tergantung pada tampang lintang aktivasi serta laju peluruhan dan pembentukan nuklida induk.
\end{abstract}

Kata kunci: bahan fisil, bahan non fisil, PWR, ORIGEN-ARP 5.1

\begin{abstract}
MASS CHANGES ANALYSIS OF FISSILE AND NON FISSILE MATERIALS IN THE PWR 1000 MWe USING ORIGEN-ARP 5.1. Controlled fission reaction occurs in the reator core. Reactor components such as fuel, cladding and cooling water have an important role in the sustainability of the fission reaction. Fission reaction causes the formation of a number of fission product nuclides and activation products. Fission product nuclides are produced from thermal neutron capture reaction of fissile material while the activation products are originated from interaction of non-fissile materials such as cladding material and coolant by neutron and gamma. At each of reactor operation, the information of fuel material changes in the form of non-fissile or fissile material, is very usefull for the management of core fuel, such as for reactivity control, optimization and loading of fuel. Hence, it needs to perform a research in the fissile and non-fissile material changes in the reactor core. This can be done by observing the change of material mass in the reactor core. The objective of this research is to determine the change in mass of material in the core, such as the mass of the nuclear fuel elements, cladding and cooling water after use in the core. From mass changes can be delivered to burn up calculation or fuel consumption level. The calculation were performed on the basis of the United States PWR 1000 MWe by using a fission inventory computer code of ORIGENARP 5.1, a new version of ORIGEN with specific library for nuclear power plant. The analysis results show that the U-235 fissile material having a mass reduction up to 58\% or more than half from the initial U-235 mass for each operation cycle period. Fertile material $U-238$ was reduced by about $2 \%$ only from the initial mass for each operating cycle period. For other cases, the non-fissile material case, mass changes reduced in various for each operation cycle, depend on activation cross-sections and decay and formation rate of parent nuclides.
\end{abstract}

Keyword: fissile material, non fissile material, PWR, ORIGEN-ARP 5.1 


\section{PENDAHULUAN}

Teras reaktor nuklir merupakan suatu tempat berlangsungnya reaksi pembelahan (fisi) yang terkendali. Untuk dapat mengendalikan laju dari reaksi fisi tersebut, suatu reaktor nuklir harus didukung oleh beberapa hal, diantaranya adalah adanya komponen reaktor nuklir yang memiliki standar dan kualitas yang tinggi dan handal. Salah satu komponen reaktor yang berperan penting adalah bahan bakar nuklir. Terdapat dua jenis bahan bakar nuklir yaitu bahan fisil (fissile material) dan bahan fertil (fertile material). Bahan fisil ialah suatu unsur atau atom yang langsung dapat memberikan reaksi pembelahan apabila berinteraksi dengan neutron termal (reaksi tangkapan), seperti U-235 dan $\mathrm{Pu}-239$. Sedangkan bahan fertil ialah suatu unsur atau atom yang setelah menangkap neutron tidak dapat langsung membelah, tetapi akan membentuk bahan fisil, seperti U-238 yang akan menjadi bahan fisil $\mathrm{Pu}-239$ setelah menangkap satu neutron [1].

Pengoperasian suatu reaktor nuklir, selain mengakibatkan terbentuknya unsur-unsur radioaktif hasil fisi dalam bentuk produk fisi (fission products) serta aktinida dan anak luruhnya (actinide and daughters), juga dihasilkan sejumlah hasil aktivasi (activation products). Hasil aktivasi ini berasal dari bahan non fisil, seperti material kelongsong (cladding) dan air pendingin dalam teras, yang berinteraksi dengan radiasi gamma dan neutron. Pada setiap pengoperasian suatu reaktor, informasi perubahan material bahan bakar pada setiap siklus operasi, baik dalam bentuk bahan fisil ataupun non fisil, sangat penting untuk manajemen bahan bakar dalam teras, seperti pengaturan reaktivitas, optimasi dan pemuatan bahan bakar. Untuk itu diperlukan kajian mengenai proses perubahan material dalam teras reaktor, salah satunya dengan mengamati perubahan massa dari material dalam teras reaktor, baik bahan fisil maupun non fisil. Perubahan massa dapat dinyatakan dalam persentase ataupun fraksi bakar (burn up). Unsur-unsur radioaktif yang terbentuk selama pengoperasian reaktor atau disebut sebagai inventori, berperan juga sebagai sumber radiasi atau source term dalam teras reaktor yang berguna untuk perhitungan laju dosis dan paparan radiasi dalam teras. Penelitian ini memiliki tujuan untuk mengetahui perubahan massa unsur penyusun material dalam teras, seperti massa dari bahan fisil dan non fisil dari unsur penyusun elemen bahan bakar nuklir, kelongsong dan air pendingin setelah digunakan dalam teras.

Tinjauan kualitatif tentang zat radioaktif sebagai suku sumber yang terlepas dari reaktor daya tipe air tekan (PWR) telah dilakukan oleh Suharno (2007) [2]. Perubahan massa bahan bakar dalam bentuk tingkat konsumsi bahan bakar atau fraksi bakar dari reaktor daya tipe PWR dari Jepang berdaya 1100 MWe telah diteliti oleh Jati S dkk (2006) dengan hasil tingkat konsumsi bahan bakar 85,61\% pada fraksi bakar $50 \mathrm{MWd} / \mathrm{kg}$ dan 90,94\% pada fraksi bakar $60 \mathrm{MWd} / \mathrm{kg}^{[3]}$. Rohanda A dkk (2008) juga telah melaporkan hasil kajian fraksi bakar pada reaktor daya jenis PWR dari Korea Selatan pada kelas daya yang sama dengan fraksi bakar rata-rata hingga $72 \%$ untuk tiap siklusnya[4]. Tingkat konsumsi bahan bakar dalam teras sangat dipengaruhi dan sebanding dengan fraksi bakar atau daya yang digunakan. Analisis radioaktivitas inventori reaktor daya tipe PWR berdaya 1000 MWe pada 1 siklus operasi telah dilakukan oleh Rohanda (2012) dengan menggunakan ORIGEN2.1 [5]. Pada makalah ini, penelitian dilakukan dengan cara menganalisis inventori hasil fisi pada kasus irradiasi material homogen teras reaktor daya PWR dari Amerika Serikat berdaya 1000 MWe dengan menggunakan ORIGEN-ARP 5.1 dengan library khusus reaktor daya sebagai tools penghitung. Inventori hasil fisi terhitung dianalisis dengan membandingkan massa unsur tiap penyusun teras mulamula dengan massa unsur pada akhir siklus operasi hingga 3 siklus operasi yang disajikan dalam bentuk persentase perubahan massa, yang merepresentasikan pola pemuatan pada 3 jenis tingkat pengkayaan bahan bakar reaktor jenis PWR. Penggunaan ORIGEN-ARP telah cukup dikenal untuk perhitungan deplesi dan manajemen bahan bakar oleh para peneliti dari KAERI (Korea Atomic Energy Research Institute) [6,7]. Rohanda dkk juga telah melakukan verifikasi hasil perhitungan ORIGENARP terhadap ORIGEN2.1 pada kasus analisis jumlah dan jenis inventori pada 3 siklus reaktor daya 1000 MWe [8]. Hasil verifikasi menunjukkan bahwa setelah mengalami 3 siklus operasi, massa bahan fisil penyusun teras menunjukkan hasil yang sama pada unsur hidrogen, oksigen, zirkonium dan niobium sedangkan pada kategori bahan fisil U-235 menunjukkan perbedaan sebesar 10,92\%. Hasil verifikasi lainnya yaitu jumlah nuklida inventori yang dihasilkan lebih banyak dari pada hasil analisis dengan ORIGEN2.1. Tidak ada perbedaan signifikan pada jumlah inventori yang dihasilkan untuk kategori produk aktivasi antara ORIGEN-ARP dengan ORIGEN2.1. 


\section{TEORI}

ORIGEN atau Oak Ridge Isotope GENeration and depletion code adalah program komputer yang dikembangkan oleh Divisi Teknologi Kimia dari Oak Ridge National Laboratory (ORNL) sebagai program simulasi siklus bahan bakar dalam reaktor dan peluruhan radioaktif. Code ORIGEN dapat dijumpai dalam versi ORIGEN2.1, yang diperkenalkan sejak tahun 1991 dan versi ORIGENARP 5.1 yang diperkenalkan tahun 2006. ORIGEN-ARP 5.1 atau yang berarti ORIGEN dengan Automatic Rapid Processing merupakan versi windows dari ORIGEN2.1 yang telah dilengkapi Graphical User Interface (GUI) yang terdapat dalam modul program besar SCALE 5.1 [9]. ORIGENARP 5.1 didesain digunakan untuk perhitungan deplesi, analisis inventori dan peluruhan radioaktif serta hanya dilengkapi pustaka (library) khusus reaktor daya populer seperti reaktor air tekan (PWR), reaktor air didih bertekanan (BWR), reaktor tipe CANDU, reaktor berpendingin gas AGR dan MAGNOX, reaktor dari Rusia (VVER) dan reaktor dengan bahan bakar mixed oxide (MOX) [10]. Formulasi perhitungan inventori didasarkan pada basis 1 kelompok deplesi dan peluruhan radioaktif yang dirumuskan dalam persamaan sebagai berikut [11] :

$$
\frac{d X_{i}}{d t}=\sum_{j=1}^{N} l_{i, j} \lambda_{j} X_{j}-\phi \cdot \sum_{k=1}^{N} f_{i, k} \sigma_{k} X_{k}-\left(\lambda_{i}+\phi \sigma_{i}+r_{i}\right) . X_{i}+F_{i} ; i=1,2, \ldots, N
$$

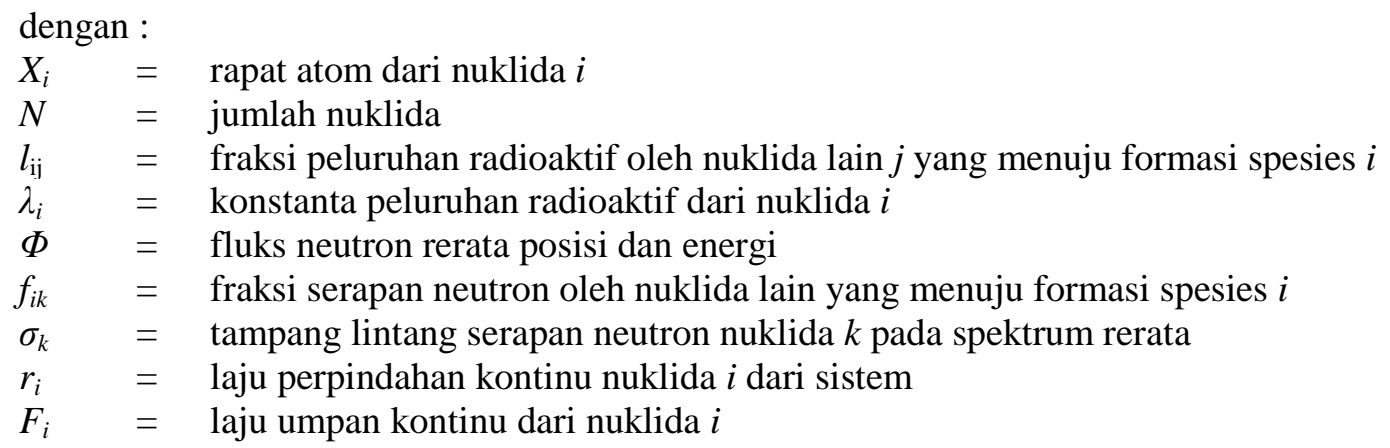

Setiap suku matematis pada persamaan di atas mencerminkan proses peluruhan, proses serapan, proses perpindahan dan pengumpanan nuklida radioaktif yang terlibat pada perhitungan inventori dalam teras reaktor.

Ukuran konsumsi bahan bakar dalam reaktor sering kali dinyatakan dalam bentuk fraksi bakar atau burn up. Fraksi bakar dapat dinyatakan dalam persentase atom atau massa yang mengalami reaksi fisi atau perbandingan massa akhir dengan massa awal sebelum mengalami reaksi fisi dalam teras. Fraksi bakar juga dapat dinyatakan sebagai banyaknya energi yang dihasilkan per satuan berat bahan bakar dalam reaktor [1]. Rapat cacah atom dari berbagai isotop di dalam teras reaktor secara terusmenerus berubah. Perubahan ini disebabkan oleh proses reaksi inti seperti pembelahan, tangkapan neutron dan peluruhan radioaktif seperti diformulasikan dalam persamaan 1. Peristiwa fisi atau pembelahan akan mengurangi konsentrasi bahan fisil seperti U-235 dan Pu-239. Proses tangkapan neutron akan mengurangi konsentrasi bahan fertil kemudian menghasilkan sejumlah konsentrasi hasil transmutasi uranium (transuran) seperti $\mathrm{Pu}-239$ dan sejumlah besar produk nuklida hasil belah.

\section{TATA KERJA}

Penelitian ini dilakukan dengan mempersiapkan data teknis PLTN tipe PWR 1000 MWe dari pabrikan Westinghouse dari Amerika Serikat terlebih dahulu. Data teknis yang dipersiapkan berupa daya termal, siklus operasi, data massa unsur penyusun material dalam teras, seperti massa dari unsur penyusun elemen bahan bakar nuklir, kelongsong dan air pendingin setelah digunakan dalam teras, jenis perangkat bahan bakar dan grup energi gamma seperti ditunjukkan pada Tabel 1. Data-data tersebut digunakan sebagai data masukan (input) code ORIGEN-ARP 5.1. 
Tabel 1. Data teknis PLTN PWR 1000 MWe Amerika Serikat sebagai data masukan ORIGEN-

ARP 5.1 [12]

\begin{tabular}{clc}
\hline No. & \multicolumn{1}{c}{ Parameter } & Keterangan \\
\hline 1 & Daya termal reaktor (daya elektrik) & $3400 \mathrm{MW}(1000 \mathrm{MWe})$ \\
2 & Data operasi tiap siklusnya : & \\
& a. Waktu operasi & 18 bulan $(12.492 \mathrm{jam})$ \\
& b. Waktu padam & 17 hari $(408 \mathrm{jam})$ \\
3 & Tingkat pengkayaan U-235 & $2,35 \% \quad 3,40 \% 4,45 \%$ \\
4 & Massa penyusun teras & \\
& a. Total massa bahan bakar & $95.974,62 \mathrm{~kg}$ \\
& b. Total massa kelongsong & $19.552,08 \mathrm{~kg}$ \\
& c. Total massa air pendingin & $195.044,56 \mathrm{~kg}$ \\
5 & Jenis library perangkat bahan bakar & Westinghouse $17 \times 17$ \\
6 & Grup energi gamma & 18 grup ORIGEN \\
\hline
\end{tabular}

Tahapan selanjutnya adalah memverifikasi hasil perhitungan inventori ORIGEN-ARP 5.1 dengan hasil perhitungan dengan ORIGEN2.1. Setelah verifikasi dilakukan, dilanjutkan dengan menganalisis hasil keluaran (output) dari ORIGEN-ARP 5.1. Massa inventori hasil fisi terhitung (dalam 'gram'), dianalisis dengan cara membandingkan massa unsur tiap penyusun teras mula-mula dengan massa unsur pada akhir siklus operasi hingga 3 siklus operasi. Hasil analisis kemudian disajikan dalam bentuk persentase perubahan massa.

\section{HASIL DAN PEMBAHASAN}

Analisis perubahan massa unsur Uranium (U), baik U-235 dan U-238 dilakukan dengan menggunakan code ORIGEN-ARP 5.1 selama 3 siklus operasi dalam teras PLTN PWR 1000 MWe. U-235 merupakan bahan fisil sedangkan U-238 berperan sebagai bahan fertil. Persentase perubahan massa U-235 dan U-238 selama 3 siklus operasi ditunjukkan pada Gambar 1.

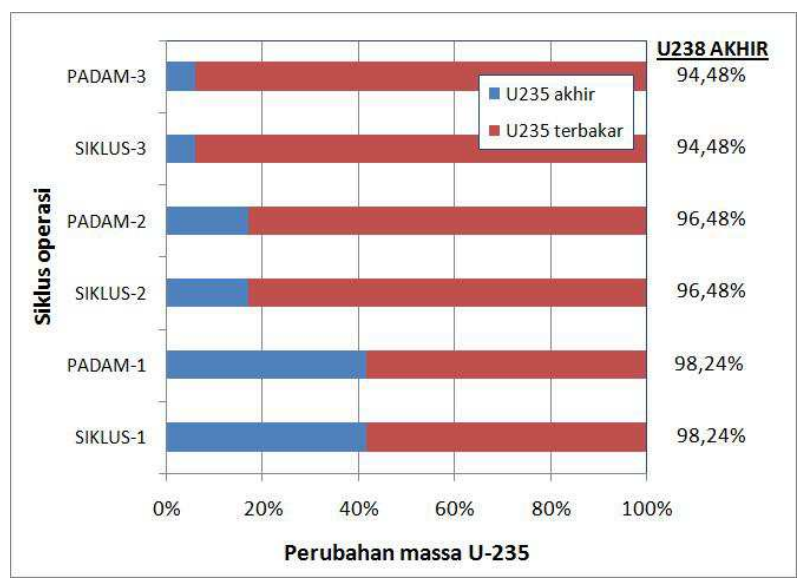

Gambar 1. Persentase perubahan massa bahan fisil dan fertil penyusun teras PWR 1000 MWe

Secara umum, massa U-235 sebagai bahan fisil berkurang hingga lebih dari separuhnya atau tepatnya 58,20\% tiap kali siklus operasi. Pada siklus operasi ke-1, massa U-235 berkurang hingga tinggal $41,80 \%$, pada akhir siklus ke-2 tinggal $17,14 \%$ dan pada akhir siklus ke-3 tersisa $6,12 \%$ dari massa U-235 semula. Sehingga dapat dikatakan U-235 'terbakar' atau mengalami reaksi pembelahan hingga terus berkurang massanya. Apabila dibandingkan dengan tingkat konsumsi U-235 pada reaktor daya PWR dari Jepang (sekitar 80\%) [3] dan dari Korea Selatan (sekitar 70\%) [4] pada kelas daya yang sama, maka tingkat konsumsi bahan fisil U-235 pada reaktor daya PWR Amerika Serikat lebih rendah, yaitu hanya sekitar 60\%. Dari sisi neutronik, semakin rendah massa U-235 akhir dapat berakibat 
rendahnya tingkat reaktivitas lebih (excess reactivity) bahan bakar dalam teras, sehingga akan mempengaruhi proses pembakaran selanjutnya. Ditinjau dari aspek ekonomi, dengan semakin sedikitnya bahan fisil yang tersisa hal ini menunjukkan efisiensi penggunaan bahan bakar fisil U-235 semakin tinggi.

Hasil yang berbeda ditunjukkan pada U-238 sebagai bahan fertil. Massa U-238 berkurang sangat sedikit tiap kali siklus operasi. Hingga 3 siklus operasi, massa U-238 tersisa masih 94,48\%. Seperti diketahui, umumnya perangkat bahan bakar (fuel assembly) dalam reaktor dibedakan menjadi 3 jenis berdasarkan tingkat pengkayaan U-235. Pada AP1000 misalnya, memiliki tingkat pengkayaan $2,35 \%, 3,50 \%$ dan $4,45 \%$ [12]. Perangkat bahan bakar dengan tingkat pengkayaan tertinggi digunakan selama 3 siklus operasi, sedangkan perangkat dengan tingkat pengkayaan paling rendah hanya digunakan untuk 1 siklus operasi saja, lalu dikeluarkan dari dalam teras untuk diganti dengan bahan bakar baru (fresh fuel). Gambar 1 di atas juga memberikan informasi bahwa selama reaktor padam 17 hari tiap siklusnya, massa unsur uranium tetap dan tidak berkurang. Hal ini disebabkan saat reaktor padam tidak terjadi reaksi fisi yang dapat mengakibatkan pengurangan massa. Faktor waktu (waktu reaktor padam atau waktu peluruhan) hanya mampu mempengaruhi nilai aktivitas dan bukan massa.

Selain bahan fisil dan fertil, didalam teras reaktor juga didapati adanya bahan non fisil yang merupakan bahan pendukung dan berasal dari material perangkat bahan bakar, material kelongsong hingga air pendingin yang berperan juga sebagai moderator pada tipe reaktor daya jenis air tekan (PWR). Perubahan massa bahan non fisil ditunjukkan dalam Tabel 2.

Tabel 2. Persentase perubahan massa bahan non fisil penyusun teras PWR $1000 \mathrm{MWe}$

\begin{tabular}{ccccccc}
\hline \multirow{2}{*}{ Nuklida } & \multicolumn{5}{c}{ Perbandingan massa akhir dengan massa awal (\%) } \\
\cline { 2 - 7 } & \multicolumn{2}{c}{ Siklus-1 } & \multicolumn{2}{c}{ Siklus-2 } & \multicolumn{2}{c}{ Siklus-3 } \\
\cline { 2 - 7 } & operasi & shutdown & operasi & shutdown & operasi & shutdown \\
\hline H & 100,07 & 100,07 & 100,07 & 100,07 & 100,14 & 100,14 \\
$\mathrm{C}$ & 133,17 & 133,17 & 167,10 & 167,10 & 206,26 & 206,26 \\
$\mathrm{~N}$ & 99,72 & 99,72 & 99,44 & 99,44 & 99,13 & 99,13 \\
$\mathrm{O}$ & 100,00 & 100,00 & 100,00 & 100,00 & 100,00 & 100,00 \\
$\mathrm{Si}$ & 100,00 & 100,00 & 100,00 & 100,00 & 100,00 & 100,00 \\
$\mathrm{Fe}$ & 100,00 & 100,00 & 100,00 & 100,00 & 100,00 & 100,00 \\
$\mathrm{Zr}$ & 101,18 & 101,18 & 101,96 & 101,96 & 102,70 & 102,70 \\
$\mathrm{Nb}$ & 102,17 & 102,11 & 101,46 & 101,41 & 101,04 & 100,99 \\
$\mathrm{Sn}$ & 102,63 & 102,62 & 105,45 & 105,44 & 108,59 & 108,58 \\
$\mathrm{Hf}$ & 99,15 & 99,12 & 97,76 & 97,71 & 95,76 & 95,70 \\
\hline
\end{tabular}

Tabel 2 menunjukkan bahwa sebagian bahan non fisil memiliki massa yang sedikit berkurang atau hampir tetap dan sebagian lainnya justru bertambah di akhir siklus operasi. Bahan non fisil seperti unsur Nitrogen $(\mathrm{N})$ dan Hafnium (Hf) diakhir operasi menjadi berkurang massanya karena telah berubah menjadi unsur lain, misalnya karena aktivasi oleh neutron dan gamma. Unsur seperti Hidrogen $(\mathrm{H})$, Oksigen $(\mathrm{O})$, Silikon $(\mathrm{Si})$ dan Besi $(\mathrm{Fe})$ cenderung tidak mengalami perubahan massa, hal ini disebabkan laju peluruhan nuklida induk dan pembentukan nuklida induk sama. Unsur lainnya seperti Karbon $(\mathrm{C})$, Zirkonium $(\mathrm{Zr})$, Niobium $(\mathrm{Nb})$ dan Timah $(\mathrm{Sn})$ mengalami penambahan massa diakhir siklus operasi. Hal ini disebabkan adanya sumbangsih dari radionuklida anak dan cucu yang dihasilkan selama terjadi reaksi inti dalam teras hingga 3 siklus operasi.

\section{KESIMPULAN}

Dari hasil dan pembahasan dapat disimpulkan bahwa bahan fisil U-235 mengalami pengurangan massa sekitar 58\% (lebih dari separuhnya) dari massa awalnya untuk tiap kali siklus operasi sedangkan bahan fertil U-238 mengalami pengurangan massa sekitar $2 \%$ dari massa awalnya tiap kali siklus 
operasi. Bahan non fisil mengalami perubahan massa yang berbeda-beda untuk tiap kali siklus operasinya tergantung tampang lintang aktivasi dan laju pembentukan dan peluruhan radionuklida induk.

\section{UCAPAN TERIMA KASIH}

Penulis mengucapkan terimakasih kepada Drs. Amir Hamzah, M.Si, Ir. Pudjijanto MS dan Ir. Tagor Malem Sembiring atas segala saran, arahan dan bimbingan selama kegiatan penelitian dan penulisan KTI berlangsung.

\section{DAFTAR PUSTAKA}

1. BATAN, "Glosarium Ilmu dan Teknologi Nuklir", Penerbit BATAN, Jakarta, (2002).

2. SUHARNO, "Zat Radioaktif sebagai Suku Sumber yang Terlepas dari Reaktor Daya PWR", Sigma Epsilon vol. 11 No. 1 Februari, hal. 9-14 (2007).

3. SUSILO J. dan TUKIRAN, "Pemodelan Perangkat Bahan Bakar PWR dalam Perhitungan kinf Menggunakan SRAC-ASMBURN", Prosiding Seminar Nasional ke-12 Teknologi \& Keselamatan PLTN serta Fasilitas Nuklir, 12-13 September, Hal. 108-120, Yogyakarta (2006).

4. ROHANDA A. dan PUDJIJANTO MS., “Analisis Fraksi Bakar Elemen Bakar Nuklir dalam Teras Reaktor PWR 1000 MWe”. Prosiding Seminar Nasional Pengembangan Energi Nuklir, 18 Juni, Hal 340-349, Jakarta (2008).

5. ROHANDA, A., "Analisis Radioaktivitas pada Teras dan Sistem Pendingin Primer PLTN PWR Tipe AP1000", Tesis Magister Fisika ITB Bandung (2012).

6. PARK, C.J., PARK, J.H., MOON, J.S., SONG, K.C., Depletion Calculation of the Irradiated Dry Process Fuel Using ORIGEN-ARP, Proceedings of the KNS Spring meeting, Korea Atomic Energy Research Institute (2010).

7. CHO, D.K., CHOI, J.W., LEE, J.Y., CHOI, H.J., KIM, S.K., Comparison of ORIGEN-2 and ORIGEN-ARP for Spent Fuel Management, Proceedings of the KNS Spring meeting, Korea Atomic Energy Research Institute (2011).

8. ROHANDA A. dan HAMZAH A., "Verifikasi Hasil Perhitungan ORIGEN-ARP Terhadap ORIGEN2.1 pada Kasus Analisis Inventori 3 Siklus Teras PLTN PWR 1000 MWe", Prosiding Pertemuan dan Presentasi Ilmiah - Penelitian Dasar Ilmu Pengetahuan dan Teknologi Nuklir 2014, 10-11 Juni, Hal. 16-21, Yogyakarta (2014).

9. HORWEDEL J.E., "A Guide to Using ORIGEN-ARP Graphical User Interface“, SCALE5.1 manual book, Revision updated October 26 (2006).

10. GAULD, I.C., BOWMAN, S.M., HORWEDEL, J.E., “ ORIGEN-ARP: Automatic Rapid Processing for Spent Fuel Depletion, Decay and Source Term Analysis “, ORNL/TM2005/39, Revision 5.1, Vol. I, Book 2, Sect. D1, November (2006).

11. CROFF, A.G., ORIGEN2 : a Versatile Computer Code for Calculating The Nuclide Compositions and Characteristic of Nuclear Material, Nuclear Technology Vol. 62, September (1983).

12. US-NRC, “Advanced Passive 1000 Design Control Document ", Westinghouse Electric Company LLC, January 27 (2006). 